\title{
The Impact of Covid-19 Pandemic on International Students Observing Self Quarantine and Physical Distancing
}

\author{
Md. Sayed Uddin
}

Sociology and Social Anthropology, Faculty of Social Sciences and Humanities, Universiti Malaysia Sabah, Jalan UMS, 88400, Kota Kinabalu, Sabah, Malaysia

\author{
Adam Andani Mohammed (Corresponding Author) \\ Social Work Studies, Faculty of Social Sciences and Humanities, \\ Universiti Malaysia Sarawak, Kota Samarahan Sarawak, Malaysia.
}

Received: Apr. 18, 2021 Accepted: Jun. 2, $2021 \quad$ Online published: Jul. 12, 2021

doi:10.5296/ijhrs.v11i3.18855 URL: https://doi.org/10.5296/ijhrs.v11i3.18855

\begin{abstract}
The new coronavirus disease (COVID-19) which spread across the globe has no effective treatment or vaccine and calls for other ways to control its infection are needed. The disease easily spread among people in close contact through cough and/or sneeze. This prompted the World Health Organisation WHO to recommend other ways of controlling the disease to include quarantine, isolation and social distancing where people without the symptoms are distanced from one another. Students may experience loneliness, anxiety, depression, and insomnia due to self-quarantine and other issues like social isolation, perceived dangers, uncertainty in relation to study, physical discomfort, fear of virus infection from others, negative news in the mass media. As such, international students who are far from home were invited as respondents to explore the effect of these control measure on those under self-quarantine. A qualitative online interview protocol was sent to the locations of these students at Sungai Chinchin in Gombak and international student hostel Sabah. To be eligible, respondents should be international students and observing self-quarantine.
\end{abstract}

Keywords: Malaysia, Covid-19, coronavirus, international student, quarantines, lockdown, pandemic 


\section{Introduction}

The unfavorable impact of coronavirus COVID-19 pandemic is still continuing and causing devastating damage all over the world. It is unique in many ways and its impact is tremendous and varied, complex and evolving. No one is safe from this pandemic regardless of country of origin, race, gender, religion, rich or poor, black or white, citizens or non-citizens, migrants and refugees or rural and urban. The COVID-19 outbreak already affected the daily social lives and livelihoods, education and health, business and economics of individuals, families, communities, students, indigenous peoples, migrants and minority groups. At the time of writing (as of May 05, 2020) 215 countries were affected by Coronavirus disease (COVID-19) with 3181642 confirmed cases and 224301 confirmed deaths worldwide (WHO, 5 April 2020) ${ }^{1}$. The common consciousness around the world about its threats and implications is obvious. In fact, it will be the first epidemic where the long term implications could be recognized as they happen. Its effects are major disruptions to the global economy and education through dislocation of normal personal relationships, as no individual or family, community, country, or business has escaped its impacts.

Universities from around the world have been uncertain about how long the coronavirus crisis will last and how it might affect the mental health of students and faculty (Araújo et al., 2020). In fact, for the time being in the course of the COVID-19 outbreak, technologies are playing a vital role more than ever before in keeping the society and educational institutions functional in a time of lockdowns and quarantines. As many institutions has started right ways to keep students informed and busy in their academic activities. The World Health Organization WHO immediate after the COVID-19 pandemic announced that almost every sector from business, education, communication to entertainments people are dependent on the technology. The education sector is one of the key sectors using technology to conduct distance learning during this pandemic. It was reported that 191 countries announced or implemented school or university closures, impacting 1.57 billion students as of mid-April. Many educational institutions started offering courses online to ensure education was not disrupted by quarantine measures (Yan Xiao \& Ziyang Fan, World Economic Forum: 27 Apr 2020). To curb the spread of the disease, one measure implemented in many countries is minimizing close contact between people ("physical distancing"). Engaging in physical distancing is a prosocial act in the sense that it helps protect other individuals, especially those most vulnerable to the virus (Pfattheicher et al., 2020). According to UNESCO reports, it is reported that about 290 million students now stuck at home while more than 160 nations have implemented national closures of their educational institutions due to the covid-19 virus which represent $87,1 \%$ of the total students enrolled (UNESCO, 04 March 2020). A study conducted by Abidah, et al. (2020) has also indicated the similar situation in mentioning that about 165 countries in Asia, Europe, Africa, the Middle East, South America and North America have imposed restrictions on schools and universities. As huge number of students who are potentially at risk are from pre-primary to high school level is 577,305,660 and at higher education level is 86,034,287 (Nugroho, 2020 cited in Abidah, et al., 2020). Despite still only being in the early stage of the COVID-19 pandemic, a rapidly growing body of

\footnotetext{
${ }^{1}$ See detail https://www.who.int/emergencies/diseases/novel-coronavirus-2019
} 
research into social responses to the virus is emerging (Harper et al., 2020). Yet, few studies focused on the impact of covid-19 pandemic on international students observing self-quarantine and physical distancing. Like other students, the international students are also stuck overseas in their college hostels or residents during the pandemic. Thousands of international students are observing self-quarantine in various part of Malaysia. It is interesting and a problematic phenomenon to understand their experiences while observing self-quarantine and physical distancing.

To slow the spread of the virus, governments from all over the world have taken measures to ensure foreign students' safety that includes guidelines and advice for international students from the ministry of higher education. Malaysia is also not exception. According to media reports, Malaysia was hosting 127,583 international students as of March $2019-70 \%$ of which were in private higher education institutions. In 2019, 30,341 international students were enrolled at public higher education institutes, statistics show (Viggo Stacey, Sep 27, 2019). To curb the virus the government of Malaysia has implemented Movement Control Order (MCO) in phases thus from $18^{\text {th }}$ March 2020 to $9^{\text {th }}$ June 2020. Education Malaysia Global Services (EMGS) under the purview of the Ministry of Higher Education Malaysia, a company that deals with foreign students has committed to ensuring all international students stay informed and safe. In their official website they provide COVID-19 guidelines and advice for international students.

\section{Literature Review}

Pandemic has been a serious cause of great anxiety in the population. Maria et al. (2020) investigated student's levels of anxiety during the pandemic time and compared that with normal times. They wanted to explore whether the degree of anxiety, depression, and stress in university students have changed during the period of the pandemic (2020) compared with the previous normality. Their findings revealed that students during the time of the pandemic showed higher degree of stress, anxiety and depression in contrast with students in normal times. They noted that the pandemic has a negative psychological effect on students. Another recent study by Mohammed et al. (2020) focuses on symptoms of stress of students observing self-quarantine under the Movement Control Order (MCO) during the COVID-19 pandemic in Malaysia. They have pointed out several symptoms of stress as students were frustrated due to poor internet network while self-quarantine, some said they feel stress due to limited view, plenty of time but less to do, no place to go, and lack of physical contact of people as before. Villani et al. (2021) found similar results while investigating students in an Italian university. A total 501 students participated the study to whom $35.33 \%$ were found anxious and $72.93 \%$ as depressed. Most importantly $70 \%$ suffered from the impossibility of physically seeing their partners and friends. They noted that being female student was associated to an increase in the occurrences of anxiety. They point out that the pandemic is uncertain, and it may lead long-term effects on student's mental health. Their study concluded that it is crucial to investigate the highly useful interventions to detect vulnerable subgroups and to plan for critical and long-term psychological services to reduce and control the burden of psychological problems. 
At the same time, education institutions in all over the world have been taken a series of programs and initiatives to prevent the virus spread. Recently in a study conducted by Sarker et al. (2021) investigated the preventive and supportive measures taken by the university towards international students in China. According to authors, the success of such Covid 19 campaigns and preventive measures such as mask wear, restrictive physical exercise, daily health reporting and preventive and supportive steps largely depends on student's satisfaction, awareness building and trust on the authorities. An online based survey was conducted among 467 international students in China, indicated that the supportive and preventive measures provided by the respective authorities or institution or taken by students were positively related to students' satisfaction. Similarly, further, it was found that the trust gained in authorities also showed a positive direction. Their research shows that preventive and supporting actions have a significant impact on the growth of student satisfaction, with contented students having a major influence on the establishment of sufficient trust in their institutions.

\section{Methods}

This research uses a qualitative approach to create a position paper that persuades the reader that the viewpoints stated are valid and justified. Abdul Razzak, (2020) described such a study as conceptual analyses in methodology. In a study by Fleming (2020) has rightly mentioned that there are few important steps in writing a position paper. To him, a position paper consisting of few steps as it begun with selecting a topic and do the preliminary research, secondly, challenge the topic and search for supporting evidence and define study outline (Fleming, 2020). The present study sent out an online interview protocol survey in mid-April 2020 to examine the experience of International students observing self-quarantine in and around Sungai Chinchin in Gombak and international students along Jalan Kingfisher, Jln USM Sabah.

\section{Data collection and analysis}

A total of 30 students were chosen for the study using a purposive sampling technique. They were sent an online interview protocol and then made direct phone calls to support their responses, opinions, and arguments. This technique is supported by many studies, since protocol is a predetermined sheet on which one logs information learned during the observation or interview as the interview protocol was used to enable the researchers to take information from the respondents (Neuman \& Neuman, 2006; Crouch \& McKenzie, 2006; Tong et al., 2007). At one point the interview protocols were received and reviewed to extract sentences and phrases which were related to the issue under investigation. Themes were generated to discover those meanings hidden in the phrases in the various contexts of the investigated phenomenon which are announced in the original protocols. With an analytical mind, the researchers found transition in meaning perceived as stress symptoms due to quarantine and physical distancing of students. At this point, all the results were organized and gathered into a descriptive form and by doing so the researchers discovered the impact of Covid 19 pandemic on international students while observing self-quarantine at the study area. 


\section{Macrothink}

\section{Findings}

The international students observing self-quarantine and physical distancing experiences were shared by the respondent's finds multifaceted responses on the impact of COVID -19 pandemic. The number of salient themes that emerged were discussed as below.

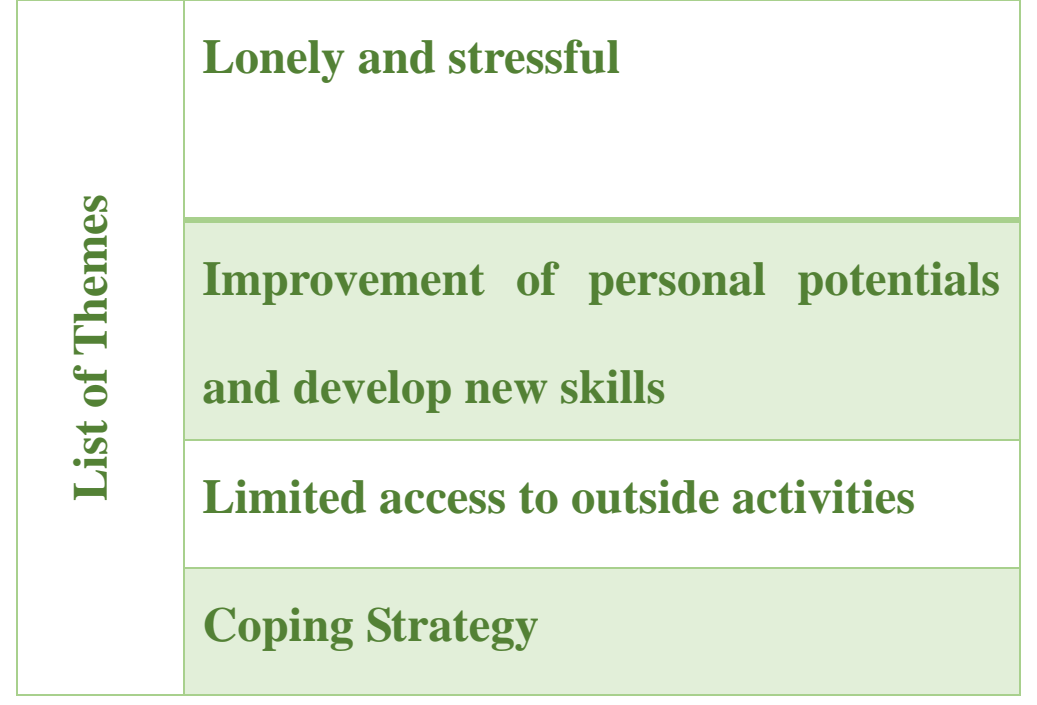

Figure 1. List of themes based on the international students observing self-quarantine and physical distancing experiences

\section{Lonely and stressful}

The majority of respondents have shared both positive and negative experiences while observing social distances when they were maintaining self-quarantine under $\mathrm{MCO}$ in Malaysia. One of the respondent (Participant A) express her opinion about how she spent time during COVID-19 outbreak, she states:

"Self-indulging (reading books, journals, novels, watching some movies and facial treatment), try some new experience on the one hand, many programs are delayed and even canceled, because planning the program in 2020 has come a long way ... many things are interrupted and a lot of things delays, programs that have been arranged into chaotic and I can't go outside like usually. Boring, stressful, sometime I can't do anything".

Majority respondents obviously find life very stressful while they are observing self-quarantine in their hostel. But the main and important reasons are that they were full of anxiety and feeling lonelier. According to a respondent (Participant B):

"anxiety in sort of economic, academicals, and the safety of loved ones back home ... the lack of nutrition due to spending a day without sunlight, and the change of diet and lifestyle ... for me, dealing with anxiety and the change in lifestyle makes me have difficult times ... ass MCO was implemented, we go grocery shopping less than before therefore the diet has changed, we get tired mentally more than physically hence I have sleeping problems ... and staying at home makes it difficult to remain the motivation for working by myself so 
as a positive impact, I can say that we can protect ourselves from the virus. As a negative side, the change of lifestyle lets people feel ... anxiety and mentally unhealthy."

Moreover, a respondent (Participant C) described his experience as:

"I feel safer to quarantine myself .... it's better to stay inside the house however, staying inside the house makes me feel unproductive and unmotivated. It makes me feel unhealthy physically and mentally ... but but, I believe this MCO is efficient and under the high awareness of danger of this virus, it naturally makes me stay and obey the order without making any reason to go outside."

Another respondent (Participant D) replied:

"The Covid-19 pandemic has created fear and tension among people following the fact that it is unprecedented and has no vaccine. The Covid-19 pandemic has affected my postgraduate studies at the ... everything has come to a halt, and we are currently observing a Movement Control Order (MCO), which is a lockdown of some sort ... self-quarantine has the tendency to impact adversely on the economy as productivity slows down as a result of people not going to work. But it is very necessary in terms of containing and avoiding the spread of the Covid-19 pandemic. Sometimes I feel my freedom of movement is somehow being curtailed, but I think it is a necessary step to contain and avoid the spread of the Covid-19 pandemic."

\section{Improvement of personal potentials and develop new skills}

In line with this it was found that students had very hard time when the Movement Control Order (MCO) has been extended from Phase 1 which started from $18^{\text {th }}$ March 2020 to gradual extensions until Phase 5 ( $9^{\text {th }}$ June 2020). Some of the students find staying at campus hostels or at home is just take care of themselves and getting money from the parents to survive during MCO. As another respondent (Participant E) shared her experiences, she states:

"first couple of days were good. because I can rest, eat, sleep and play games but after the MCO has extended I really find difficulties to spend my time and I realize, busy life is much better and overall quite balanced these Restricted Movement Order is really a challenging situation for us, students ... it requires us to do more works in home, which I am not great on it ... it puts so much pressure for me and on the positive side, it allows us to gather with family and spending time together which for me is a rare moment. Besides, I get to develop and discovers some skills that I didn't realize I have. For the negative side, the RMO has pretty much killing me inside since I am that kind of person who cannot stuck with the same person for more than 3 days ... moreover, it hurts to see those who have to go to works everyday due to the fact that their revenue is daily."

Similarly, respondent (Participant F) has also shared experiences as he described that 
"self quarantine its an opportunity to improve personal potential or the hidden skills and knowledge. My experience of Covid-19 pandemic is about adapting to news ways of taking studies and unearthing my hidden potentials ... adapting to the use of dry foods and prayers that include how to cope the Ramadan. Improvement of personal potentials (covering tutorials I could not get time to cover) so bored but developing my knowledge and potentials."

On contrary, other respondent (Participant G) as he found the first phase of MCO more challenging. He shared

"In first two weeks, it was quite stressful ... however, once my university starts contacts with us, I became more calm. I take this opportunity to work on my assignment and enjoy the calm and relax life also, there are so many online stores that facilitate the challenge of MCO but there is not enough consultation with your lectures which make me became more independent in ... studying and assignments and the positive side in this time - it makes me think more about my lifestyle, in term of type of food things that I consumed ... do I exercise enough? am I satisfied in the way I spend my time? In negative side I can say-only in the beginning for MCO, it was quite stressful and we do not know how to manage things ... so far, I can handle it, but I hope it ends as soon as possible”.

\section{Limited access to outside activities}

Like all other people around the world, the students were also not prepared for such a so sudden unknown environment they are going through. The question is what they can do and what they cannot do while self-quarantine due to COVID-19 outbreak. One student (Participant H) shared that:

"Lifestyle became limited and access to outside world is very limited as well as daily activities and there are few like cannot go to mosque to pray I cannot go to gym to exercise and as well as limited access to outside activities ... positive... yes more self-time and negative 1 less active these days. 2 gaining weight. At the beginning it was boring now I have come up with a daily routine to coupe up with the boredom and the utilizing the time in an efficient way." Another respondent states same way that "adjusting to new situations. Creating doubts about people you come in contact with because of pandemic. Demonstrate the ability to be more vigilant with regard to your health ... constantly remaining indoors, wearing of face mask, Inability to Socialise. It help release stress having time to connect you're your family Create strong bond within household. Negative; Financial constraint, Uncertainties, bored."

As mentioned that respondents shared both positive and negative ways of experiencing of self-quarantine time in hostels or at residents (outside hostel). One of the respondents 
(Participant I) shared that:

"Covid-19 pandemic gave me lot of experiences in my personal life as well as social life. Staying at home all the time, without friends and social gathering is a whole new experience. Doing online classes, submitting assignments and group projects online is also a new experience. And living with a fear of getting the virus all the time is a bad experience. Going out to buy things that I need, couldn't go back to my country for my semester break. During this self-quarantine you get to spend some time with yourself which is a good thing, and can develop a new skill and try something new to keep yourself busy. The negative side would be getting bored of staying alone, getting depressed, and thinking about useless things which creates more restlessness in yourself. I have mixed feeling all the time. Sometimes I am happy, sometimes I am sad and depressed limiting ourselves in room for a quite long time."

Some of them shared similar experiences that they are getting less active day by day. According to a respondent (Participant J), she stated like (Participant $\mathrm{H}$ )

"Lifestyle became limited and access to outside world is very limited as well as daily activities. There are few like cannot go to mosque to pray. Cannot go to gym to exercise and as well as limited access to outside activities. The positive things in self quarantine is that I have more self-time. On negative side I must say that less active these days. As a result, gaining weight. At the beginning it was boring now I have come up with a daily routine to coupe up with the boredom and the utilizing the time in an efficient way."

\section{Coping Strategy}

Coping strategy is important while the international students were observing self-quarantine since $18^{\text {th }}$ March 2020. After MCO implemented in Malaysia some of the students had planned and strategies the daily activities in order to be more productive, healthy and stay motivated. A respondent (Participant C) shared with researchers that :

"I always plan every day to do the some work. I must have goals and then try some new and don't forget to exercise to avoid stress maybe play with cat also. I hope this pandemic will be done as soon as possible, and for the next we must aware with cleanliness and also how we applied healthy life in anywhere anytime."

Another respondent (Participant K) shared his coping strategy, he states:

"I found difficulties but still managed to cope up. I tend to fill my days with several kinds of activities, so it doesn't really feel bored to stay home ... although I often get stress I fill each day with different activities and try to be more productive at home ... I know it's hard to holding on during this self-quarantine and it involves people from all around the world ... thus, my suggestion is just enjoy this moment even though it's hard but the more you 
think about it, the more you will get stress and so, just let it flow and don't forget to eat healthy, workout more often, try to be more productive and control your mental health."

Some of the students reported that they tried to get connected with their family and friends by sharing many important information about health issues and the daily routine activities they are doing while quarantine. According to respondent (Participant L),

"Since I am far from my country where the awareness was still low, I tried to send messages to my friends and people in the country. Other than that, I tried to reach other International students asking how they are doing, giving information I got and showed I care. And I tried not to buy unnecessarily, thinking about elder people who need more good and nutrition. I call my family and friends who are away from me, I try to cook food that is good in nutrition and entertains my housemates who feel anxiety as well. .. yes besides, I try to focus more on that I feel excited to study and not focus too much on the news about covid-19. Starting new things also makes me feel better, productive and motivates me. It's completely normal to feel anxiety or stress during the time we face financial and social crises. I would like to suggest that you share your feelings with someone you can talk to, that you try to maintain your lifestyle by workout and proper sleeping schedule, and that you use your time properly to keep motivating and feeling joy in small things. Since we don't have this much time we can use freely, I truly believe that we should not focus on negativity but stay positive and use this time to invest yourself after everything gets better."

Another respondent (Participant M) mentioned that:

"I plan my day and follow a schedule. Try to do things I could not do before. Try to create new hobbies. Keep in contact with my friends and family back home. By try to think of alternative ways to manage things and keep optimistic. People must thing of what kind of lessons this pandemic gives us. Maybe it is time to think of the way we live. Also, we must give our mental and physical health a priority in our daily life."

Even some of them have spent their time watching movies, listening to music. As mentioned by a respondent (Kapil), "Learning new things, watching movies, volunteering to my University Covid-19 sewing brigade." Another responded (Participant N) stated that

"I engage in several activities which include studying, exercising, and entertaining myself through movies and important programs online. I maintain a positive mental attitude believing that something positive will come out of our endurance."

Another response from respondent (Participant O)

"I try to keep myself busy, by watching series, movies. I try to do some studying as well. I try to cook something new. Not really. I just stay by myself 
and do things I like to do. Think about good things, happy things. Keep yourself busy by doings things you like. Do meditation, stay positive and help people around you to stay positive"

\section{Discussion}

The purpose of this study is to investigate the impact of covid-19 pandemic on international students observing self-quarantine and physical distancing. Majority of the international students reported both positive and negative impact of the COVID-19 pandemic. The World Bank is also concerned about the impact of COVID-19 on international student's present conditions during this pandemic. It stated that "With campus closures, there have been mass displacements of tertiary students, including repatriation of international students and staff. Student support networks and access to vital services have been greatly diminished. Students (and staff) are experiencing the physical and mental-health impacts of the disruptions" (World Bank, May 2020: p.23).

It was indicated by respondents that the first phase of MCO they find quite challenging to adjust themselves. But when the university started to communicate with them through online learning then they became quite busy and active. Even many reports on issues relating to international students' responses to the coronavirus outbreak and how to deal with this new situation, many were published since the OCVID-19 outbreak begun. Since the outbreak, students were advised to stay at hostel colleges or their residences to observe self-quarantine avoid the spread and being infected. Findings indicate that majority of international students experienced stress, worry and living with fear during this outbreak. Aliran (2 May 2020) had reported that international students are caught between returning to their families in their home countries and staying on in their host nations to continue their studies. Initial anxieties arose over the uncertainty over how their learning would take place. At the same time the internationals students are also worried about the safety of their family members back home (country of origin). For many international students, the lockdown and restrictions may also affect their mental state.

Public health emergencies can have much psychological effect on college students, which can be expressed as fear and worry, anxiety, and among others. Results of correlation analysis indicated that economic effects, and effects on daily life, as well as delays in academic activities, were positively associated with anxiety symptoms (Cao et al. 2020). Recently, a study conducted on levels of anxiety among college students during the epidemic in China, Cao et al. (2020) found that $0.9 \%$ of the respondents were experiencing severe anxiety, $2.7 \%$ moderate anxiety, and $21.3 \%$ mild anxiety. It was found that living with parents had a significant effect on anxiety, such that students living alone had increased anxiety. Moreover, students from rural areas, families without a steady income, not living with parents, and having a relative or an acquaintance infected with COVID-19, were more likely to be severely anxious. They suggested that the mental health of college students should be monitored during epidemics. Blended learning was, thus, introduced as a tool in personalised learning to adjust to the new realities. According to Araújo et al. (2020), these are unprecedented circumstances, and the need to understand they create stress, favoring anguish 
and a fierce search for new knowledge acquisition. Araújo et al. (2020) noted that anxiety and depression, exacerbated by uncertainties and intensification of the information flow, will grow extensively. Negative physiological consequences of stress will manifest. For instance, loneliness, which increases under these circumstances, seems to have a negative impact on education and, therefore, create psychological pain and suffering (Araújo et al. (2020).

Simlarly, Shahyad and Mohammadi (2020) noted that the COVID-19 disease will not only raise public health concerns but also cause several psychological distress, including anxiety, fear, depression, stigmatization, avoidance behaviors, irritability, insomnia and posttraumatic stress disorder (PTSD). They noted that in this situation, the maintenance of mental health status of individuals is very important because people in different parts of society may experience additional stressors during the COVID-19 outbreak. Individuals in different parts of a society may experience the psychological symptoms to COVID-19 during the rising phase of the outbreak, including patients of COVID-19, quarantine individuals, health care workers and family members of medical staffs, children, university students, pregnant women, and families. In this regard, there is the strong evidence that the mental health status of these populations is vulnerable to exhibition of the psychological disorders symptoms.

\section{Conclusion}

The world is going through a global health crisis under COVID-19 pandemic. A crisis that confined thousands of people self-quarantine, which is only a remedy to curb the spread of the virus and slow its dangers as of now. The disease easily spread among people in close contact through cough and/or sneeze. This prompted the World Health Organisation WHO to recommend other ways of controlling the disease to include quarantine, isolation and social distancing where people without the symptoms are distanced from one another. As presented in the findings, majority of international students have experienced various economic, social and psychological challenges while they were observing self-quarantine to combat the virus. It was reported that many international students experienced stress, anxiety and living with fear while self-quarantine during the MCO in Malaysia. Findings indicate that the first Phase of the MCO was not okay for some students as they felt stressful while others reported first couple of days they felt relaxed and tried to watch movies and other fun activities. Days passed by they experience more anxiety in sort of economic, academicals, and the safety of loved ones back home. Many students find they had improved in some new skills and become more independent in their study and assignments as the face-to-face consultations were not possible at all. It was also found that some respondents felt unproductive and demotivated during this whole self-quarantine time. More importantly, the international students reported that sometimes they felt unhealthy physically and mentally as well.

\section{References}

Abdul Razzak, N. (2020). Paulo Freirees critical and dialogic pedagogy and its implications for the Bahraini educational context. Educational Philosophy and Theory, (Article in press). https://doi.org/10.1080/00131857.2020.1716731 
Abidah, A., Hidaayatullaah, H. N., Simamora, R. M., Fehabutar, D., \& Mutakinati, L. (2020). The Impact of Covid-19 to Indonesian Education and Its Relation to the Philosophy of "Merdeka Belajar". Studies in Philosophy of Science and Education, 1(1), 38-49. https://doi.org/10.46627/sipose.v1i1.9

Aliran, A. (2 May 2020). Covid-19 blues: Away from home, international students face added stress. Accessed online at https://aliran.com/new-writers/covid-19-blues-away-from-home-international-students-face-a dded-stress/

Araújo, F. J. D. O., de Lima, L. S. A., Cidade, P. I. M., Nobre, C. B., \& Neto, M. L. R. (2020). Impact Of Sars-Cov-2 And Its Reverberation In Global Higher Education And Mental Health (Letter)(Open Access). $\quad$ Psychiatry 288. https://doi.org/10.1016/j.psychres.2020.112977

Cao, W., Fang, Z., Hou, G., Han, M., Xu, X., Dong, J., \& Zheng, J. (2020). The psychological impact of the COVID-19 epidemic on college students in China. Psychiatry research, 112934. https://doi.org/10.1016/j.psychres.2020.112934

Crouch, M., \& McKenzie, H. (2006). The logic of small samples in interview-based qualitative research. Social science information, 45(4), 483-499. https://doi.org/10.1177/0539018406069584

Harper, C. A., Satchell, L. P., Fido, D., \& Latzman, R. D. (2020). Functional fear predicts public health compliance in the COVID-19 pandemic. International journal of mental health and addiction. https://doi.org/10.1007/s11469-020-00281-5

Maia, B. R., \& Dias, P. C. (2020). Ansiedade, depressão e estresse em estudantes universitários: O impacto da COVID-19 = Anxiety, depression and stress in university students: The impact of COVID-19. Estudos de Psicologia, 37. https://doi-org.ezproxy.ums.edu.my/10.1590/1982-0275202037e200067

Mohammed, A. A., Uddin, M. S., \& Saidi, A. M. (2020). Covid-19 And Movement Control

Order: Stress and Coping Strategies of Students Observing Self-Quarantine. International Journal of Academic Research in Business and Social Sciences, 10(5), 788-802.

Neuman, W. L., \& Neuman, W. L. (2006). Social research methods: Qualitative and quantitative approaches. University of Wisconsin U.S A. MA: Allyn and Bacon Publisher.

Pfattheicher, S., Nockur, L., Böhm, R., Sassenrath, C., \& Petersen, M. B. (2020). The emotional path to action: Empathy promotes physical distancing during the COVID-19 pandemic. Online access on 23 May 2020 Retrieved from file:///D:/Cureent\%20file/Adam\%20and\%20Me\%20paper\%20new\%20_corona_/Pfattheicher $\% 20$ et\%20al\%20_\%20Empathy\%20promotes\%20physical\%20distancing.pdf

Mei, S. L., Yu, J. X., He, B. W., \& Li, J. Y. (2011). Psychological investigation of university students in a university in Jilin province. Med Soc (Berkeley), 24(05), 84-86. 


\section{Macrothink}

International Journal of Human Resource Studies ISSN 2162-3058 2021, Vol. 11, No. 3

Sarker, T., Sarkar, A., \& Rabbany, M. G. et al. (2021). Evaluation of preventive, supportive and awareness building measures among international students in China in response to COVID-19: a structural equation modeling approach. glob health res policy 6, 10 . https://doi.org/10.1186/s41256-021-00192-5

Shahyad, S., \& Mohammadi, M. T. (2020). Psychological impacts of Covid-19 outbreak on mental health status of society individuals: A narrative review (Review). Journal of Military Medicine, 22(2), February 2020, Pages 184-192.

Tong, A., Sainsbury, P., \& Craig, J. (2007). Consolidated criteria for reporting qualitative research (COREQ): a 32-item checklist for interviews and focus groups. International Journal for Quality in Health Care, 19(6), 349-357. https://doi.org/10.1093/intqhc/mzm042

UNESCO. (04 March 2020). 290 million students out of school due to COVID-19: UNESCO releases first global numbers and mobilizes response. Online accessed at https://en.unesco.org/news/290-million-students-out-school-due-covid-19-unesco-releases-fir st-global-numbers-and-mobilizes

United Nations. (2020). Coronavirus update: 290 million students now stuck at home. Retrieved from (access 28 May 2020) https://news.un.org/en/story/2020/03/1058791

Viggo, S. (Sep 27, 2019). Malaysia to recalibrate its strategy as 200k int'l student target by 2020 looks unlikely. The Pie News. https://thepienews.com/news/malaysia-to-recalibrate-strategy-as-200000-target-looks-out-of-r each/

Villani, L., Pastorino, R., \& Molinari, E. et al. (2021). Impact of the COVID-19 pandemic on psychological well-being of students in an Italian university: a web-based cross-sectional survey. Global Health 17, 39. https://doi.org/10.1186/s12992-021-00680-w

World Bank. (2020). The COVID-19 Pandemic: Shocks to Education and Policy Responses. World Bank, Washington, DC. (C) World Bank. https://doi.org/10.1596/33696

Yan, X., \& Ziyang, F. (27 April 2020). 10 technology trends to watch in the COVID-19 pandemicWorld Economic Forum. Accessed online at https://www.weforum.org/agenda/2020/04/10-technology-trends-coronavirus-covid19-pande mic-robotics-telehealth/

\section{Copyright Disclaimer}

Copyright for this article is retained by the author(s), with first publication rights granted to the journal.

This is an open-access article distributed under the terms and conditions of the Creative Commons Attribution license (http://creativecommons.org/licenses/by/4.0/). 